Original article

Red Beetroot Thematic Issue

\title{
Optimisation of Beetroot Juice Encapsulation by Freeze-Drying
}

\author{
Vesna T. Tumbas Šaponjac, Jasna M. Čanadanović-Brunet, Gordana S. Ćetković, \\ Mirjana V. Jakišić, Jelena J. Vulic**, Slađana S. Stajčić, Vanja N. Šeregelj
}

\author{
Faculty of Technology, University of Novi Sad, Bulevar cara Lazara 1, 21000 Novi Sad, Serbia
}

Key words: beetroot, phenolics, betalains, antioxidant activity, encapsulation

\begin{abstract}
Sensitivity of natural antioxidants could be improved using encapsulation technologies. In this study, encapsulation of beetroot juice (BJ) with soy proteins has been optimized in terms of the wall:core ratio, BJ dilution and mixing time of both components, maximizing DPPH radical scavenging activity (SA) and the encapsulation efficiency (EE) based on the total phenolics content. Multi response optimization has indicated that the optimal encapsulation is accomplished when soy protein is mixed with undiluted BJ at a wall:core ratio of $50 \mathrm{~g} / \mathrm{L}$ for $9.8 \mathrm{~min}$. Applying these conditions, the optimal encapsulate has been produced, where the contents of total phenolics, flavonoids and betalains were $150.71 \mathrm{mg} \mathrm{GAE} / 100 \mathrm{~g}, 9.31 \mathrm{mg}$ RE/100 g, and $521.28 \mathrm{mg} / 100 \mathrm{~g}$, respectively, while EE and SA were in accordance with the values obtained by optimization, i.e. $92.48 \%$ and $1.01 \mathrm{mmol} \mathrm{TE} / 100 \mathrm{~g}$, respectively, confirming the validity of the optimization process. The resulting encapsulates have favorable physicochemical and functional characteristics and can be potentially applied as natural color additives.
\end{abstract}

\section{LIST OF ABBREVIATIONS}

$\mathrm{a}_{\mathrm{w}}$ - water activity; $\mathrm{BE}$ - betanin equivalents; $\mathrm{BJ}$ - beetroot juice; CPC - core phenolic compounds; DW - dry weight; $\mathrm{EE}$ - encapsulation efficiency; GAE - gallic acid equivalents; $\mathrm{OE}$-optimal encapsulate; $\mathrm{RE}$-rutinequivalents; $\mathrm{RP}$-reducing power; RSM - response surface methodology; SA - DPPH radical scavenging activity; SPC - surface phenolic compounds; SPI - soy protein isolate; TE - Trolox equivalents; VE - vulgaxanthin-I equivalents.

\section{INTRODUCTION}

Human body produces reactive oxygen and nitrogen species which, when imbalanced with antioxidants as protective mechanisms, can contribute to cellular aging and endanger health [Poljsak et al., 2013; Valko et al., 2007]. Overproduction of these reactive species results in oxidative stress, which is known to cause damage to biological molecules such as lipids, proteins and nucleic acids [McCord, 2000]. Antioxidants in cells scavenge excessively produced damaging species.

Fruit and vegetables are a rich source of antioxidant compounds such as ascorbic acid, carotenoids, flavonoids, and other phenolics [Rouanet et al., 2010]. Research has shown that many chronic diseases are diet-induced [López-Varela et al., 2002]. It has been suggested that a diet rich in fruit and vegetables might strengthen the antioxidant de-

\footnotetext{
* Corresponding Author: E-mail: jvulic@uns.ac.rs (J.J. Vulić) tions, protecting them from deterioration [Shahidi \& Han,

fense network endogenously, and contribute to protection from oxidative damage.

Beetroot (Beta vulgaris L.) is a vegetable cultivated for its roots rich in betalains, water-soluble nitrogenous pigments which include betacyanins colored from purple to violet and betaxanthins with colors from yellow to orange formed in the root [Chevallier, 1996] Betalain profile in a plant depends on its maturity degree, variety, and climatic conditions [Ampleatil et al., 2015]. Betalains are commonly used as natural food dye (E162), but also have potential health benefits due to their antioxidant and anti-inflammatory activities [Georgiev et al., 2010; Zielinska-Przyjemska et al., 2009]. Beetroot contains also phenolic acids such as $p$-coumaric, protocatechuic, ferulic, vanillic, $p$-hydroxybenzoic, and syringic [Kujala et al., 2000].

The sensitivity of natural compounds, such as betalains and phenolics, to environmental or technological process conditions (temperature, $\mathrm{pH}$, oxygen content, water activity, light, radiation, presence of metal ions and redox enzymes) could be improved by microencapsulation [Krajka-Kuzniak et al., 2012; Ravichandran et al., 2013]. Pitalua et al. [2010] have found that betalain content, color, antioxidant activity, and redox potential of beetroot juice encapsulated in gum Arabic obtained were stable during storage for 44 days at $\mathrm{a}_{\mathrm{w}}<0.521$. Also, betalains from Lampranthus productus have been stable during six months of storage when spray dried with maltodextrin or chitosan [Gandía-Herrero et al., 2013]. This technology presents packing target molecules in capsules which release the content at controlled rates and condi- 
1993]. One of the most widely used techniques of microencapsulation is freeze-drying which is based on the phenomenon of sublimation. Its main advantage is that the most of the favorable properties of raw material, e.g. shape, dimensions, appearance, taste, color, flavor, texture, and bioactivity, remain preserved [Ceballos et al., 2012]. Saikia et al. [2015] found a higher efficiency of the encapsulation process and retention of phenolics in the freeze-dried samples compared to the spray-dried ones, and explained that by the large surfaces area exposed to air and high temperatures used in the spray drying technique.

The materials used as the wall of an encapsulate in food usually include protein isolates, gum Arabic, pectin, skim milk powder, non-fat dry milk solids, soy, modified starch, maltodextrin and sugars, which are food-grade and biodegradable [de Vos et al., 2010; Nedovic et al., 2011]. A soy protein isolate (SPI) is a well-known food carrier, due to its high purity, low cost, availability, high nutritional value, and functional properties such as solubility; the ability to absorb water and oil, the ability to stabilize emulsions; the ability to form gels, foams and films; as well as its fine organoleptic properties [Franzen \& Kinsella, 1976; Maltais et al., 2009; 2010].

This study was designed to investigate the optimal conditions for beetroot juice (BJ) encapsulation using soybean proteins, using the freeze-drying method. The optimal conditions for obtaining the encapsulates with the highest encapsulation efficiency (based on the total phenolic compound content) and the highest antioxidant activity against the stable DPPH radicals were defined with the response surface methodology (RSM). The optimal encapsulate (OE) was characterized regarding its physicochemical characteristics; total phenolics, flavonoid and betalain contents; antioxidant activity against DPPH radicals; and reducing power.

\section{MATERIAL AND METHODS}

\section{Reagents, chemicals and instruments}

The Folin-Ciocalteau reagent, 2,2-diphenyl-1-picrylhydrazyl radical $\left(\mathrm{DPPH}^{\bullet}\right)$, 6-hydroxy-2,5,7,8-tetramethylchroman-2-carboxylic acid (Trolox), and trichloroacetic acid were purchased from Sigma Chemical Co. (St Louis, MO, USA); ferric chloride was obtained from J.T. Baker (Deventer, Holland); and sodium nitrite from LACH-NER (Brno, Czech Republic). Other chemicals and solvents used were of the highest analytical grade. Distilled water was produced using the DESA 0081 Water Still destilator water purification system (POBEL, Madrid, Spain). Soy protein isolate was purchased from "Macrobiotic Prom" company (Belgrade, Serbia). Absorbances in spectrophotometrical assays were measured using a Multiskan GO microplate reader (Thermo Fisher Scientific Inc., Waltham, MA, USA) and a UV-1800 spectrophotometer (Shimadzu, Kyoto, Japan).

\section{Beetroot as plant material}

Beetroot (Beta vulgaris L.) was obtained at a local supermarket. Roots of the beet were washed, cut into pieces, and blended in a laboratory blender (model Neo SK-400, TCL King Electrical Appliances Co., Ltd., Huizhou, China).
Beetroot juice (BJ) was separated from pomace by vacuum filtration and stored at $-20^{\circ} \mathrm{C}$ until analysis.

\section{Encapsulation procedure}

The BJ (initial pH 5.45) was encapsulated via freeze-drying. BJ (core) was mixed with a soy protein isolate (wall) according to the experimental design (Table 1). The samples were frozen at $-40^{\circ} \mathrm{C}$ for $2 \mathrm{~h}$ in a Martin Crist Alpha 2-4 (Osterode, Germany) freeze-drier. The main drying process was performed at pressure of $0.01 \mathrm{mbar}$ and temperatures from -40 to $20^{\circ} \mathrm{C}$ for $59.5 \mathrm{~h}$. The final drying lasted $5.5 \mathrm{~h}$ at pressure of 0.005 mbar and temperatures from 20 to $30^{\circ} \mathrm{C}$. The collected freeze-dried samples were stored at $-20^{\circ} \mathrm{C}$ until further use. Freeze-drying experiments were executed in a laboratory freeze-drier (model Alpha 2-4 LSC, Martin Christ, Osterode, Germany), under the conditions described above.

\section{Optimization of encapsulation}

Parameters of encapsulation were optimized using the response surface methodology (RSM). The adopted experimental model was a Box-Behnken design for three variables at three levels. Three independent variables (parameters of encapsulation) were: the ratio of wall:core $\left(X_{1}\right)$, dilution of BJ $\left(\mathrm{X}_{2}\right)$, and mixing time $\left(\mathrm{X}_{3}\right)$. The coded values of the independent variables were $-1,0$, and 1 . The actual values, selected from the preliminary study, based on literature survey [Cheng et al., 2012; Ezhilarasi et al., 2013; Ramírez et al., 2015; Roopchand et al., 2013; Saikia et al., 2015; Tumbas Šaponjac et al., 2016] by the corresponding coded values of three independent variables are given in Table 1 . The complete model consisted of 15 experiments with three replicates.

For process optimization, encapsulation efficiencies (EE) and DPPH radical scavenging activity (SA) of encapsulates were chosen as the responses. Single response as well as multi response optimization were performed to enable the selection of optimal parameters for the production of the optimal encapsulate $(\mathrm{OE})$, which will be further examined.

\section{Spectrophotometric determination of the total phenolics content of beetroot juice and its encapsulates}

The content of total phenolics in BJ, in the core of encapsulates (CPC), and in the surface of encapsulates (SPC) was determined by the method with the Folin-Ciocalteu reagent [González-Molina et al., 2008]. Briefly, the reaction mixture was prepared in a 96-well microplate by mixing $170 \mu \mathrm{L}$ of distilled water, $15 \mu \mathrm{L}$ of $\mathrm{BJ} /$ encapsulate extract, $12 \mu \mathrm{L}$ of the Folin-Ciocalteu's reagent, and $30 \mu \mathrm{L}$ of $20 \%$ sodium carbonate. The mixture was incubated in the dark at room temperature for $1 \mathrm{~h}$. After incubation, the absorbance was read at $750 \mathrm{~nm}$. The corrections for interfering substances originating from beetroot have been made by simultaneous preparation of control samples with a matching concentration of BJ/encapsulate extract in the same way. Results were expressed as gallic acid equivalents (GAE) per $100 \mathrm{~mL}$ of BJ or per $100 \mathrm{~g}$ of encapsulate.

To determine the encapsulation efficiency, the total contents of phenolic compounds in the core (CPC) and surface (SPC) were evaluated using the encapsulate extraction procedure described by Vergara et al. [2014]. For CPC, 100 mg 
of the sample were suspended in $1 \mathrm{~mL}$ of an ethanol:acetic acid:water mixture $(50: 8: 42, v / v / v)$, vortexed for $1 \mathrm{~min}$, centrifuged for $2 \mathrm{~min}$ at $14,000 \times g$ (model Rotilabo-mini-centrifuge, Carl Roth, Karlsruhe, Germany), and then the supernatant was separated. For SPC, $100 \mathrm{mg}$ of the sample were suspended in $1 \mathrm{~mL}$ of an ethanol:methanol mixture $(1: 1, v / v)$. The mixture was vortexed for $1 \mathrm{~min}$, centrifuged at $3018.6 \times \mathrm{g}$ for $2 \mathrm{~min}$, and then supernatant was separated. CPC and SPC were determined with the Folin-Ciocalteu method [González-Molina et al., 2008]. The encapsulation efficiency (EE) was determined by using the equation:

$$
\mathrm{EE}(\%)=((\mathrm{CPC}-\mathrm{SPC}) / \mathrm{CPC}) \times 100
$$

\section{Spectrophotometric determination of the total flavonoid contents in beetroot juice and its optimal encapsulate}

The total content of flavonoids in BJ and OE was determined spectrophotometrically with a modified method described by Markham [1989]. The reaction mixture was prepared in a 96-well microplate by mixing $125 \mu \mathrm{L}$ of $\mathrm{BJ} / \mathrm{OE}$ extract obtained using ethanol:acetic acid:water (50:8:42, $\mathrm{v} / \mathrm{v} / \mathrm{v}), 25 \mu \mathrm{L}$ of distilled water, and $62.50 \mu \mathrm{L}$ of $\mathrm{AlCl}_{3}$. Blank sample was prepared in the same manner replacing $\mathrm{AlCl}_{3}$ with water in the reaction mixture. The absorbance was measured immediately at $430 \mathrm{~nm}$. Absorbance of the experimental samples was corrected for the absorbance of control samples with the appropriate concentration of BJ or extract encapsulated without the reagent. The total content of flavonoids was expressed as rutin equivalents (RE) per $100 \mathrm{~mL}$ of $\mathrm{BJ}$ or per $100 \mathrm{~g}$ of $\mathrm{OE}$.

\section{Determination of betalain content in beetroot juice and its optimal encapsulate}

Contents of betalain pigments (betacyanins and betaxanthin) in $\mathrm{OE}$ and $\mathrm{BJ}$ were determined as described by von Elbe [2003] in a 96-well microplate by mixing $240 \mu \mathrm{L}$ or $250 \mu \mathrm{L}$ of a phosphate buffer $(0.05 \mathrm{M}, \mathrm{pH} 6.5)$ and $\mathrm{BJ} /$ ethanol:aceticacid:water (50:8:42, v/v/v) OE. Phosphate buffer was used as a blank. Wavelengths of $545 \mathrm{~nm}$ and $476 \mathrm{~nm}$ were used for the analysis of betacyanins and betaxanthin, while the wavelength of $600 \mathrm{~nm}$ was used for correction. Total betalains content was calculated as the sum of betacyanin and betaxanthin contents. Content of betacyanins was expressed as mg betanin equivalents (BE) per $100 \mathrm{~mL}$ of juice or per $100 \mathrm{~g}$ of encapsulate, while the content of betaxanthins was expressed as mg vulgaxanthin-I equivalents (VE) per $100 \mathrm{~mL}$ of BJ or per $100 \mathrm{~g}$ of OE.

\section{Determination of radical scavenging activity against DPPH radical}

The ability of BJ and OE to scavenge DPPH radicals was determined using the spectrophotometric method which is based on monitoring changes in solution color from purple-colored stable nitrogen DPPH radicals to yellow-colored reduced non-radical form DPPH-H [Brand-Williams et al., 1995]. Samples of the encapsulate were prepared in the same way as for determination of CPC. Briefly, $250 \mu \mathrm{L}$ of a DPPH solution in methanol was mixed with $10 \mu \mathrm{L}$ of the sample (BJ or encapsulate extract) in the microplate well and left in dark at room temperature for $50 \mathrm{~min}$. Afterwards, absorbance was read at $515 \mathrm{~nm}$. The samples containing corresponding concentrations of BJ and encapsulate extracts without DPPH radicals were analyzed in parallel. Their absorbance was used to correct the absorbance of experimental samples. The following equation was used to calculate the DPPH radical scavenging activity:

$$
\mathrm{SA}(\%)=\left(\mathrm{A}_{\mathrm{C}}-\mathrm{A}_{\mathrm{S}}\right) / \mathrm{A}_{\mathrm{C}} \times 100
$$

where: $A_{C}$ is the absorbance of the control (without antioxidant) and $A_{S}$ is the absorbance in the presence of the sample (BJ or encapsulate extract) after correction. The calibration curve was made with Trolox and results were expressed as mmol of Trolox equivalents (TE) per $100 \mathrm{~mL}$ of $\mathrm{BJ}$ or per $100 \mathrm{~g}$ of encapsulate.

\section{Determination of the reducing power of beetroot juice and its optimal encapsulate}

The method of Oyaizu [1986] was used to determine the reducing power (RP) of $\mathrm{BJ}$ and $\mathrm{OE}$. OE was prepared in the same way as for determination of CPC: $25 \mu \mathrm{L}$ of the sample (BJ/OE extract), or $25 \mu \mathrm{L}$ water as a blank, $25 \mu \mathrm{L}$ of sodium phosphate buffer ( $\mathrm{pH}$ 6.6), and $25 \mu \mathrm{L}$ of $1 \%$ potassium ferricyanide, were mixed and incubated in a water bath for $20 \mathrm{~min}$ at $50^{\circ} \mathrm{C}$. When the solution was cooled, $25 \mu \mathrm{L}$ of $10 \%$ trichloroacetic acid was added and solutions were centrifuged at $3018.6 \times g$ for $10 \mathrm{~min}$ and afterwards $50 \mu \mathrm{L}$ of the supernatant with $50 \mu \mathrm{L}$ of distilled water and $10 \mu \mathrm{L}$ of $0.1 \%$ ferric chloride were mixed in a microplate well. Absorbance was measured immediately at $700 \mathrm{~nm}$. The control samples with matching concentration of BJ and encapsulate extracts were prepared in the same way. The calibration curve for this test was made with Trolox and results were expressed as mmol of Trolox equivalents (TE) per $100 \mathrm{~mL}$ of $\mathrm{BJ}$ or per $100 \mathrm{~g}$ of $\mathrm{OE}$.

\section{Water activity}

Water activity $\left(a_{\mathrm{w}}\right)$ was determined by placing approximately $3 \mathrm{~g}$ of $\mathrm{OE}$ in a sample holder of a LabSwift $\mathrm{a}_{\mathrm{w}}$-meter "Novasina" (Lachen, Switzerland) at $25^{\circ} \mathrm{C}$. The $\mathrm{a}_{\mathrm{w}}$ values were recorded after equilibration.

\section{Moisture content}

The moisture content of OE was determined according to the procedure described by Şahin Nadeem et al. [2011] by drying in an oven at $70^{\circ} \mathrm{C}$ until constant weight.

\section{Particle size distribution}

Particle size distribution of OE was determined using the Mastersizer 2000 laser diffraction particle size analyzer (Malvern Instruments, Malvern, England). The Scirocco dispersion unit was used for dispersing encapsulate in the air. The sample was added at ambient temperature until an adequate obscuration was obtained $(5-10 \%)$. The results were quantified as the volume-based particle size distribution by means of the Mastersizer 2000 software. 


\section{Statistical analysis}

All experiments were performed in triplicate and the results are presented as means \pm standard deviation $( \pm S D, n=3)$. Data were analyzed by one-way analysis of variance (ANOVA) and $t$-test, where applicable, and the least significant difference $(\mathrm{LSD})$ test $(\mathrm{p}<0.05)$. Statistical analysis was performed using Statistica 8.0 (StatSoft Inc., Tulsa, OK, USA). Optimization of experiments was conducted using Design-Expert ${ }^{\circledR}$ Version 7.0.0 (Stat-Ease, Inc., Minneapolis, MN, USA, 2005).

\section{RESULTS AND DISCUSSION}

\section{Beetroot encapsulation}

Optimization of the BJ encapsulation parameters (wall:core ratio, BJ dilution and mixing time), in terms of encapsulation efficiency (EE) and DPPH radical scavenging activity (SA), was conducted using RSM with the Box-Behnken design (Table 1). The experimental model included 15 different combinations of encapsulation parameters for the measurements of EE and SA as responses. The actual values were chosen from the preliminary studies. Encapsulation efficiency of BJ with soy protein based on total phenolics content ranged from $47.79 \%$ (experiment 13 ) to $92.47 \%$ (experiment 2 ), while the experimental values for SA were in the range from $0.03 \mathrm{mmol} \mathrm{TE} / 100 \mathrm{~g}$ (experiment 12) to $1.05 \mathrm{mmol}$ $\mathrm{TE} / 100 \mathrm{~g}$ (experiment 1). Microencapsulation of phenolics highly depends on the carrier and the technique employed. Figure 1 shows the influence of independent variables $\left(X_{1}, X_{2}\right.$, $\mathrm{X}_{3}$ ) on EE and SA of encapsulates obtained in experiments 1-15. According to the response surfaces, it can be concluded that increasing the wall:core ratio caused a slight decrease in SA and EE values. Mixing time had the same effect on the responses, while increasing dilution decreased SA and increased EE of the encapsulates.

The results of single and multi-response optimization are reported in the Table 2. When using single response optimization it was found that a high wall:core ratio $(149.50 \mathrm{~g} / \mathrm{L})$, low extract dilution (0.2), and medium mixing time (18.9 min) are needed to ensure the maximal encapsulation efficiency (93.44\%). The single response optimization was used to optimize the response SA as well. In this case, the optimal sample, with maximum SA (1.01 mmol TE/100 g) may be obtained by using relatively low wall:core ratio $(50.0 \mathrm{~g} / \mathrm{L})$, no BJ dilution (0.0) and medium mixing time (12.9 min). The conditions for producing the optimal encapsulate sample (OE) were found by using a multi response optimization, where the EE and SA values are considered at the same time, and represent
TABLE 1. Experimental design, encapsulation efficiency (EE), and DPPH radical scavenging activity (SA) of beetroot juice encapsulates.

\begin{tabular}{c|c|c|c|c|c}
\hline Exp & $\begin{array}{c}\mathrm{X}_{1} \\
(\mathrm{~g} / \mathrm{L})\end{array}$ & $\mathrm{X}_{2}$ & $\begin{array}{c}\mathrm{X}_{3} \\
(\mathrm{~min})\end{array}$ & $\begin{array}{c}\mathrm{EE} \\
(\%)^{\mathrm{a}}\end{array}$ & $\begin{array}{c}\mathrm{SA} \\
(\mathrm{mmolTE} / 100 \mathrm{~g})^{\mathrm{a}}\end{array}$ \\
\hline 1 & $50(-1)$ & $0(-1)$ & $15(0)$ & $89.07 \pm 0.40$ & $1.05 \pm 0.04$ \\
2 & $150(+1)$ & $0(-1)$ & $15(0)$ & $92.47 \pm 1.67$ & $0.99 \pm 0.05$ \\
3 & $50(-1)$ & $4(+1)$ & $15(0)$ & $91.87 \pm 0.53$ & $0.21 \pm 0.02$ \\
4 & $150(+1)$ & $4(+1)$ & $15(0)$ & $87.40 \pm 3.27$ & $0.14 \pm 0.00$ \\
5 & $50(-1)$ & $2(0)$ & $5(-1)$ & $91.07 \pm 0.17$ & $0.34 \pm 0.07$ \\
6 & $150(+1)$ & $2(0)$ & $5(-1)$ & $89.97 \pm 3.34$ & $0.10 \pm 0.00$ \\
7 & $50(-1)$ & $2(0)$ & $25(+1)$ & $84.59 \pm 4.41$ & $0.22 \pm 0.00$ \\
8 & $150(+1)$ & $2(0)$ & $25(+1)$ & $90.70 \pm 2.57$ & $0.07 \pm 0.02$ \\
9 & $100(0)$ & $0(-1)$ & $5(-1)$ & $86.29 \pm 3.55$ & $0.58 \pm 0.03$ \\
10 & $100(0)$ & $4(+1)$ & $5(-1)$ & $79.73 \pm 12.51$ & $0.08 \pm 0.01$ \\
11 & $100(0)$ & $0(-1)$ & $25(+1)$ & $89.57 \pm 2.07$ & $0.56 \pm 0.03$ \\
12 & $100(0)$ & $4(+1)$ & $25(+1)$ & $91.25 \pm 6.18$ & $0.03 \pm 0.00$ \\
13 & $100(0)$ & $2(0)$ & $15(0)$ & $47.79 \pm 3.03$ & $0.08 \pm 0.01$ \\
14 & $100(0)$ & $2(0)$ & $15(0)$ & $58.02 \pm 0.28$ & $0.11 \pm 0.00$ \\
15 & $100(0)$ & $2(0)$ & $15(0)$ & $58.83 \pm 3.44$ & $0.10 \pm 0.00$ \\
\hline
\end{tabular}

aResults are presented as mean values of three replications $\pm \mathrm{SD}$. The ratio of wall:core $\left(X_{1}\right)$, dilution of beetroot juice $\left(X_{2}\right)$ and mixing time $\left(X_{3}\right)$; TE - Trolox equivalent.

the optimal conditions that provide maximum values of both responses (Table 2).

Ramírez et al. [2015] optimized the encapsulation of model fruit juice in gum Arabic and/or maltodextrin using sprayor freeze-drying, following the concentration of gallic acid as a response. RSM optimization showed that the freeze-dried encapsulates achieved with a wall blend ratio close to $100 \%$ gum Arabic and core concentration from 10 to $20 \%$ had higher contents of gallic acid. Maltodextrin concentration of 15\% was found to be the optimal for encapsulation of beetroot juice using spray-drying [Bazaria \& Kumar, 2018]. The wall concentration in these studies was much higher than in our study (5\%), although the wall material in our study was protein, not polysaccharide. Robert et al. [2010] optimized the encapsulation of polyphenols and anthocyanins from pomegranate using maltodextrin and soy protein isolate by spray drying. Encapsulation efficiency was significantly better upon the use

TABLE 2. Single (EE and SA) and multi response (EE+SA) optimization of encapsulation parameters using response surface methodology.

\begin{tabular}{l|c|c|c|c|c|c|c|c}
\hline \multirow{2}{*}{ Optimization } & \multicolumn{3}{|c|}{ Variable codes } & \multicolumn{3}{c|}{ Variable values } & \multicolumn{2}{c}{ Optimal responses } \\
\cline { 2 - 8 } & $\mathrm{X}_{1}$ & $\mathrm{X}_{2}$ & $\mathrm{X}_{3}$ & $\mathrm{X}_{1}$ & $\mathrm{X}_{2}$ & $\mathrm{X}_{3}$ & EE (\%) & $\begin{array}{c}\text { SA } \\
(\mathrm{mmol} \mathrm{TE} / 100 \mathrm{~g})\end{array}$ \\
\hline EE & 0.99 & -0.90 & 0.39 & 149.50 & 0.20 & 18.9 & 93.44 & - \\
SA & -1 & -1 & -0.21 & 50.00 & 0.0 & 12.9 & - & 1.01 \\
EE+SA & -1 & -1 & -0.52 & 50.00 & 0.0 & 9.80 & 92.48 & 1.01 \\
\hline
\end{tabular}

The ratio of wall:core $\left(\mathrm{X}_{1}\right)$, dilution of $\mathrm{BJ}\left(\mathrm{X}_{2}\right)$ and mixing time $\left(\mathrm{X}_{3}\right)$; EE -encapsulation efficiency; SA - DPPH radical scavenging activity. 


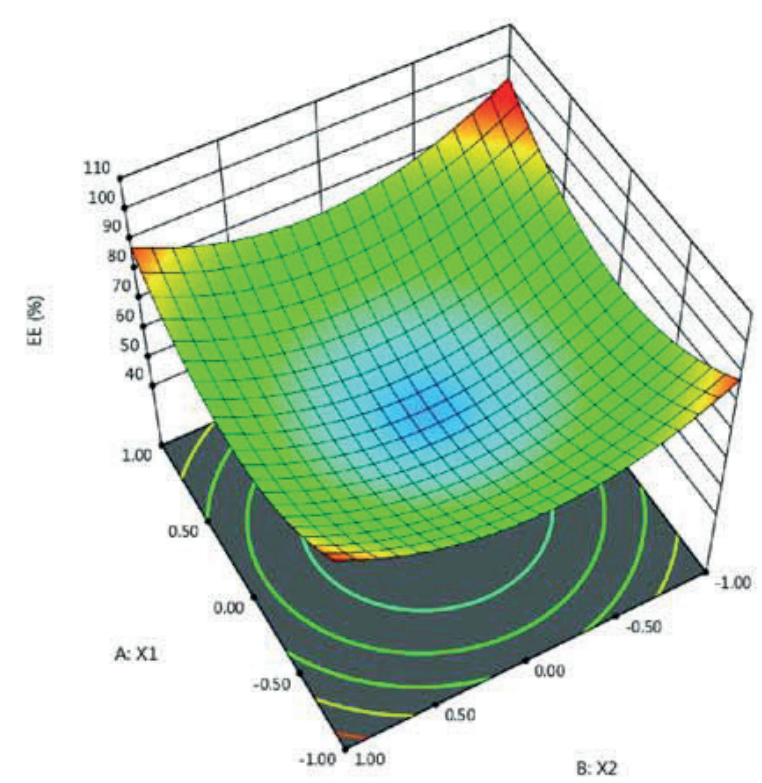

a)

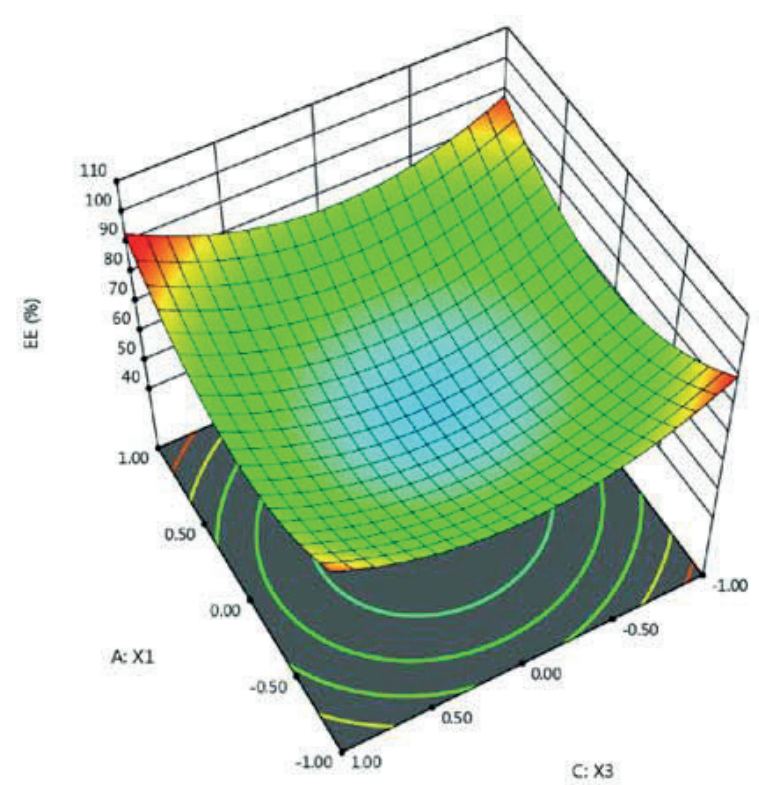

b)

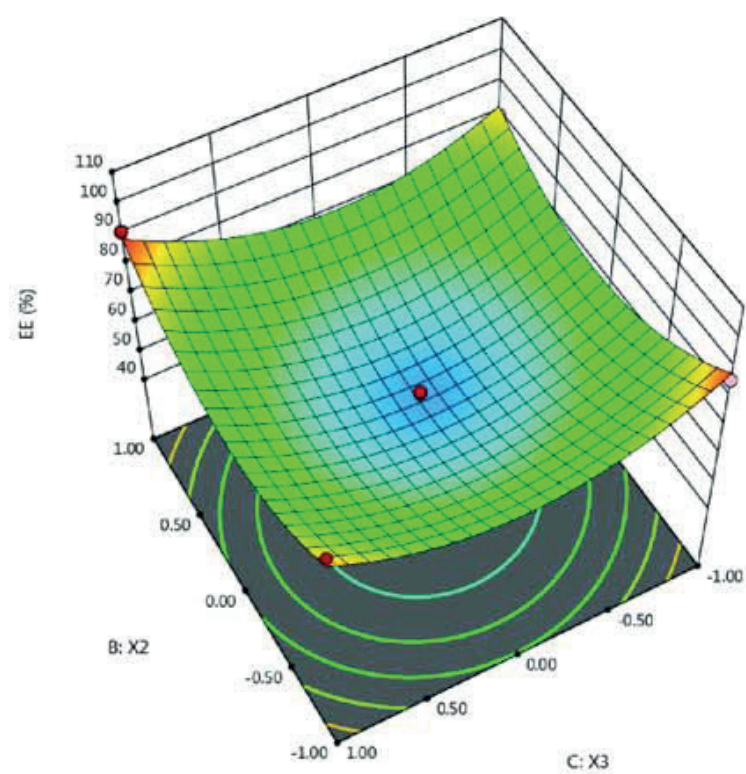

c)

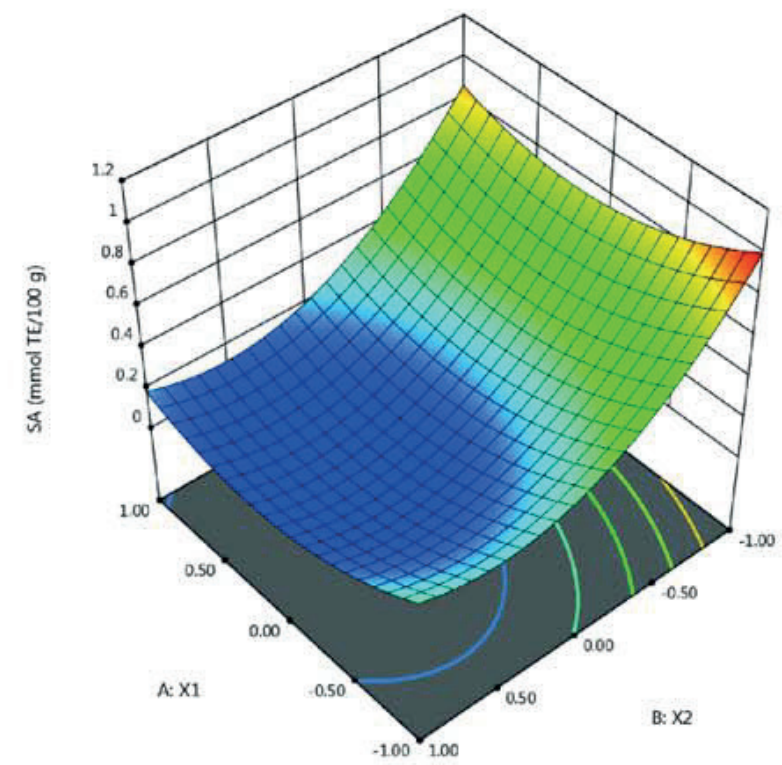

d)

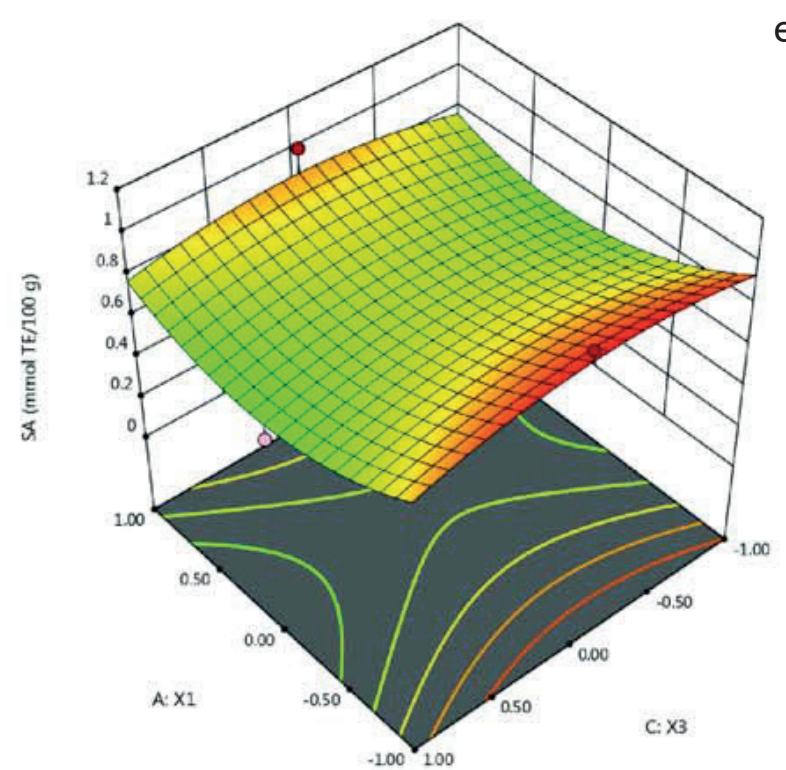

e)

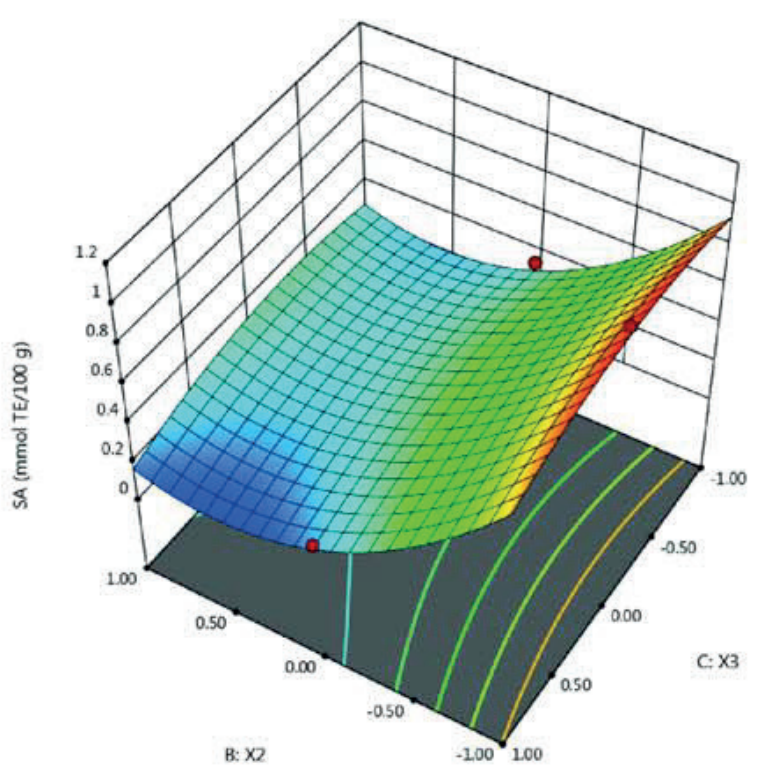

FIGURE 1. The influence of wall:core ratio $\left(X_{1}\right)$, juice dilution $\left(X_{2}\right)$, and mixing time $\left(X_{3}\right)$ on encapsulation efficiency (EE) of beetroot juice with soy protein based on total phenolics content ( $a, b$ and $c$ ) and DPPH radical scavenging activity (SA) of encapsulates (d, e and f). 
of the soy protein isolate (36.60-81.50\%). However, the encapsulation efficiency using soy protein isolate in that study was lower than in our study (47.79-92.47\%). Storage capacity of soy protein isolate was also better than that of maltodextrin, where polyphenol and anthocyanin retention increased during storage, while in the maltodextrin-based microcapsules the retention of these compounds diminished. Sprayand freeze-drying techniques require different temperature regimes and can lead to different physicochemical characteristics of encapsulates. Many factors such as light, temperature, and oxygen are considered to influence their quality.

\section{Functional characteristics of beetroot and its optimal encapsulate}

Janiszewska [2014] reported that the drying of beetroot juice is a method to obtain a pure and easy to use pigment in powder form. However, it is not possible to dry the beetroot juice without addition of carriers, because of its low glass transition temperature (measured $\mathrm{Tg}$ of juice $43 \pm 4^{\circ} \mathrm{C}$ ). In this study, we decided to use freeze-drying due to its favorable mild process parameters (low temperature) to avoid degradation of bioactive compounds from BJ. Before drying, BJ was characterized in terms of contents of total phenolics, total flavonoids, total betacyanins, and total betaxanthins, as well as free radical scavenging activity against $\mathrm{DPPH}^{\cdot}(\mathrm{SA})$ and reducing power (RP) (Table 3).

Beetroots have a high content of betalains (betacyanins and betaxanthins) that serve as color pigments [Delgado-Vargas et al., 2000]. From Table 3 it can be observed that betalains were the dominant bioactive compounds in $\mathrm{BJ}$ with their concentration reaching $236.51 \mathrm{mg} / 100 \mathrm{~mL}$, which is higher than the value of 767-1309 mg/L reported by Wruss et al. [2015]. The ratio between betacyanins and betaxanthins was from 1.75 to 1 , which is close to the value obtained in this study (0.99). However, the total phenolics content obtained in this study was much lower compared to the report of Wruss et al. [2015] (0.85-1.29 g/L). Wootton-Beard \& Ryan [2011] determined also a higher total content of phenolic compounds in the beetroot juice $(101.50 \mathrm{mg} \mathrm{GAE} / 70 \mathrm{~mL})$ than that presented in this study. Flavonoids had a small share in total phenolics content found in the BJ. Kujala et al. [2002] reported the presence of betagarin, betavulgarin, cochliophilin A, and dihydroisorhamnetin, in extracts of beetroot peel. The differences in the physicochemical characteristics of beetroot could be due to the environmental characteristics, period of harvesting, cultivar variability, and maturity stage.

Free radical scavenging activity of BJ against $\mathrm{DPPH}^{\bullet}$ was determined to be $1.93 \mathrm{mmol} \mathrm{TE} / 100 \mathrm{~mL}$ and reducing power to be $107.80 \mathrm{mmol} \mathrm{TE} / 100 \mathrm{~mL}$. Wootton-Beard \& Ryan [2011] analyzed 23 vegetable juices and found that beetroot juices displayed the highest ferric reducing antioxidant power (FRAP) values $(8355-9500 \mu \mathrm{mol} / \mathrm{L})$ and antioxidant capacity (100\% $\mathrm{DPPH}^{\bullet}$ inhibition and $92.1-92.3 \% \mathrm{ABTS}^{+*}$ inhibition) compared to the other juices analyzed (tomato, carrot, mixed vegetable, mixed fruit and vegetable). Wruss et al. [2015] found that the oxygen radical absorbance capacity (ORAC) and FRAP of beetroot juices ranged from 19.70 to $37.90 \mathrm{mmol} \mathrm{TE} / \mathrm{L}$, and from 17.40 to $37.10 \mathrm{mmol} \mathrm{TE} / \mathrm{L}$, respectively.
TABLE 3. Physicochemical characteristics of beetroot juice (BJ) and its optimal encapsulate (OE).

\begin{tabular}{|c|c|c|}
\hline Determination & BJ & $\mathrm{OE}$ \\
\hline Total phenolics content ${ }^{\mathrm{a}}$ & $56.65 \pm 1.00$ & $150.71 \pm 3.07$ \\
\hline Total flavonoids content ${ }^{\mathrm{b}}$ & $7.33 \pm 8.52$ & $9.31 \pm 0.64$ \\
\hline Total belatains content & $236.51 \pm 10.95$ & $521.28 \pm 25.52$ \\
\hline Betacyanins $^{c}$ & $117.61 \pm 10.16$ & $259.73 \pm 2.03$ \\
\hline Betaxanthins $^{\mathrm{d}}$ & $118.90 \pm 10.27$ & $261.55 \pm 2.05$ \\
\hline $\mathrm{SA}^{\mathrm{e}}$ & $1.93 \pm 0.04$ & $1.02 \pm 0.08$ \\
\hline $\mathrm{RP}^{\mathrm{e}}$ & $107.80 \pm 5.12$ & $1.81 \pm 0.04$ \\
\hline Moisture content (\%) & - & $2.61 \pm 0.12$ \\
\hline$a_{w}$ & - & $0.028 \pm 0.001$ \\
\hline Particle size $(\mu \mathrm{m})$ & - & $174.57 \pm 8.51$ \\
\hline
\end{tabular}

Data represent mean value of three replicates $\pm \mathrm{SD}$.

Results are expressed as: a mg GAE/100 mL BJ or $100 \mathrm{~g} \mathrm{OE,}{ }^{\mathrm{b}} \mathrm{mg}$ $\mathrm{RE} / 100 \mathrm{~mL} \mathrm{BJ}$ or $100 \mathrm{~g} \mathrm{OE},{ }^{\mathrm{c}} \mathrm{mg} \mathrm{BE} / 100 \mathrm{~mL} \mathrm{BJ}$ or $100 \mathrm{~g} \mathrm{OE},{ }^{\mathrm{d}} \mathrm{mg}$ $\mathrm{VE} / 100 \mathrm{~mL} \mathrm{BJ}$ or $100 \mathrm{~g} \mathrm{OE},{ }^{\mathrm{e}} \mathrm{mmol} \mathrm{TE} / 100 \mathrm{~mL} \mathrm{BJ}$ or $100 \mathrm{~g}$ OE; GAE - gallic acid equivalent; RE - rutin equivalent; $\mathrm{BE}$ - betanin equivalent; VE - vulgaxanthin equivalent; TE -Trolox equivalent; SA - DPPH radical scavenging activity; $\mathrm{RP}$ - reducig power; $\mathrm{a}_{\mathrm{w}}-$ water activity.

The OE was produced using the encapsulation parameters from multi response optimization (Table 2). Water is an important basic element in food. OE had a low moisture content $(2.61 \%)$, which corresponds to the powdered product of good stability, effective packaging and storage [do Carmo et al., 2018; Sinija et al., 2007]. Higher moisture content in products enables microbial growth and caking [do Carmo et al., 2018]. In the study of do Carmo et al. [2018], beetroot extract encapsulated in whey protein isolate alone and mixtures with maltodextrin and inulin presented higher moisture values (3.81-4.24\%) than the powders obtained with maltodextrin and/or inulin (3.33-3.58\%) because of the greater ability of proteins to maintain moisture trapped in the particles [Jayasundera et al., 2009].

The water activity $\left(\mathrm{a}_{\mathrm{w}}\right)$ measurement, often used as a critical control point for dry and dehydrated products, provides important information about the quality of a product such as the possibility of microbiological growth on the surface and sample stability and shelf-life. The control of the water activity allows preserving its structure, texture, stability, density, and the possibility of reconstitution. Water activity of the freeze-dried OE sample was found to be 0.028 , which is more than acceptable to ensure microbiological, chemical, and physical stability of the powders. Jafari et al. [2016] reported that saffron petals extract encapsulated by freeze-drying with different combinations of maltodextrin, Arabic gum, and seed cress gum had their $\mathrm{a}_{\mathrm{w}}$ values in the range from 0.07 to 0.29 and moisture content from 1.88 to $3.13 \%$. Red wine encapsulated with maltodextrin and gum Arabic, employing freeze-drying as well, had $\mathrm{a}_{\mathrm{w}}$ value of 0.11 [Rocha-Parra et al., 2016]. The results of this study indicate that water activity was a key factor affecting phenolics stability during storage. Do Carmo et al. [2018] reported color 


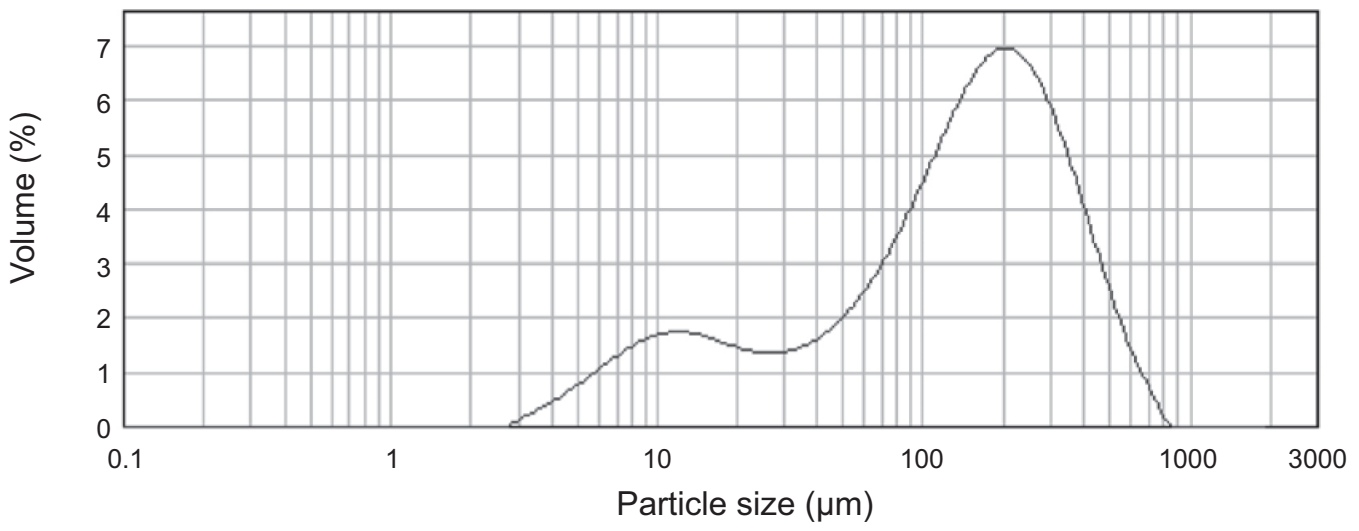

FIGURE 2. Particle size distribution of optimal encapsulate of beetroot juice.

change of the beetroot juice powders at high water activity $\left(\mathrm{a}_{\mathrm{w}}=0.843\right)$, resulting from high moisture adsorption which may have facilitated betalains hydrolysis to yellow colored betalamic acid [Herbach et al., 2006]. Pitalua et al. [2010] also concluded that the stability of betalains in microcapsules and scavenging activity depend on the $\mathrm{a}_{\mathrm{w}}$ value. They found that when $\mathrm{a}_{\mathrm{w}}$ values were in the range of $0.11-0.52$ there were no significant differences in betalains content, color, scavenging activity and reducing power, during 45 days of storage. However, during storage of encapsulates with $\mathrm{a}_{\mathrm{w}}$ values of 0.75 and 0.90 , the concentration of betalains decreased, while scavenging activity increased significantly. It is speculated that the degradation of betalains occurs through hydrolytic reaction, due to the increase of moisture in the dry product, which leads to the diffusion of oxygen within encapsulated material, causing oxidation.

The mean particle size of the OE powder was determined to be $174.57 \mu \mathrm{m}$ (Table 3, Figure 2), which is not in the range of fine powders $(<5 \mu \mathrm{m})$, as reported by Medina-Torres et al. [2013] From the particle size distribution of OE presented in Figure 2 it is evident that there are two distinct peaks representing predominant sizes, the largest volume of the OE being of the particles with diameters ranging from 100 to $300 \mu \mathrm{m}$. Kuck \& Noreňa [2016] obtained similar sizes (104.30-684.90 $\mu \mathrm{m})$ of particles of a grape skin phenolic extract encapsulated by freeze-drying. Ezhilarasi et al. [2013] reported the particle size of Garcinia fruit extract encapsulated with different wall materials, employing freeze-drying, in the range of 15-100 $\mu \mathrm{m}$. Janiszewska [2014] determined that the average diameter of spray-dried beetroot juice encapsulated in maltodextrin and gum Arabic and their mixture was in the range of 7.60-12.80 $\mu \mathrm{m}$. Man et al. [1999] reported that the particle size of spray-dried powders is usually in the range of $1-15 \mu \mathrm{m}$, while freeze-dried powder particles can reach $300 \mu \mathrm{m}$. According to Chen et al. [2012], the larger size of the particles obtained by freeze-drying could be caused by low temperatures used in this process and lack of forces for breaking up the frozen liquid into droplets or to substantially alter their surface topology during the drying process. Ramírez et al. [2015] reported that in freeze-drying the product's structure is mainly developed during the previous freezing step, where fast freezing rates generate small ice crystals and slow cooling rate generates large crystals. Kuck
\& Noreňa [2016] highlighted that due to the larger particle size freeze-dried powders have lower hygroscopicity compared to the spray-dried powders, because larger particles have smaller exposed surface area and lower water absorption rate [Tonon et al., 2010].

The content of bioactive compounds (total phenolic compounds, total flavonoids, and total betalains), and biological activity (reducing power and DPPH radical scavenging activity) were determined to characterize the OE (Table 3). According to the results obtained, flavonoids had a small contribution $(6.18 \%)$ in total phenolics content of the encapsulate as determined by the Folin-Ciocalteu assay. The content of betaxanthins (261.55 mg VE/100 g) did not differ significantly ( $p>0.05$ ) from the content of betacyanins $(259.73 \mathrm{mg}$ $\mathrm{BE} / 100 \mathrm{~g}$ ). It is evident that the content of betalains in BJ is high, which indicates a good potential of the carrier to trap betalains. Encapsulation efficiency of OE, based on the total phenolics contet, was $75.91 \%$, which is lower than the result obtained in the multi response optimization (Table 2). On the other hand, predicted SA values (Table 2) were in accordance with the values obtained for $\mathrm{OE}$ as well, without any significant difference $(\mathrm{p}>0.05)$.

Bazaria \& Kumar [2018] optimized the spray-drying of beetroot juice with whey protein concentrate. Total phenolics content of the obtained powders was in the range of 16.69-25.89 mg GAE/100 g, which is significantly lower than the value obtained in our study. It was suggested that lower inlet temperatures as well as higher addition of whey protein $(30 \%)$ could contribute to the higher preservation of phenolics during spray-drying [Bhusari et al., 2014]. Janiszewska [2014] investigated the most effective carrier that would preserve the stability of beetroot pigments. They have examined microencapsulation process using the spray-drying method and gum Arabic, maltodextrin and mixtures thereof as wall materials. The results showed that the highest yield of purple but the lowest yield of yellow pigments was obtained using gum Arabic as a carrier $(42.60 \mathrm{mg} / 100 \mathrm{~g}$ DW and $35.10 \mathrm{mg} / 100 \mathrm{~g} \mathrm{DW}$, respectively). The content of betacyanins (109-129 mg/100 g) and betaxanthins $(34-61 \mathrm{mg} / 100 \mathrm{~g})$ in this study was much lower than in our study $(259.73$ and $261.55 \mathrm{mg} / 100 \mathrm{~g})$. The results reported by do Carmo et al. [2018] demonstrate slightly lower contents for betaxanthins and betacyanins (136.86-155.37 and 
$211.93-230.10 \mathrm{mg} / 100 \mathrm{~g}$ ) in spray-dried beetroot extract powders as well. This could be attributed to the high temperatures used in spray-drying, different carriers and wall:core ratios used in the experiments as well as the differences in beetroot juice composition. Otálora et al. [2015] improved betalain content $(49.7 \mathrm{mg} / 100 \mathrm{~g})$ as well as the $\mathrm{a}_{\mathrm{w}}$ value $(0.18)$ and moisture content $(2.90 \%)$ in spray-dried cactus fruit juice by adding cactus cladode mucilage to maltodextrin as encapsulating agents. Pitalua et al. [2010] encapsulated beetroot juice using gum Arabic as a carrier and spray-drying as a method. Total betalain content in these encapsulates was even lower $(11.98 \mathrm{mg} / 100 \mathrm{~g})$, which is due to a much lower wall:core ratio $(1: 3)$ than we used in our study $(50 \mathrm{~g} / \mathrm{L}$, or 1:20), apart from above mentioned differences in experimental conditions. Ahmed et al. [2010] have reported that a higher core:wall ratio increases the content of biologically-active components in the encapsulated system.

It is generally known that the DPPH radical scavenging activity of food is closely related to the content of bioactive compounds, such as phenolics and betalains, which are present in OE. Spray-dried beetroot extract powders obtained with whey proteins and their mixtures with inulin or maltodextrin exhibited higher antioxidant activities than the inulin- and/or maltodextrin-based powders [do Carmo et al., 2018]. Authors suggest that in the case of protein-based encapsulates, antioxidant activity could be attributed not only to the bioactive compounds from beetroot extract but also to Maillard reactions occurring between sugars from beetroot extract and whey proteins.

\section{CONCLUSION}

Beetroot juice is a potential source of bioactive compounds and thus it can be used in the development of functional food. RSM was used to find the optimal conditions for producing the encapsulates of beetroot juice with soy proteins using the freeze-drying process with the highest content of phenolic compounds and the highest antioxidant activity. The optimization process was confirmed by applying the optimal conditions resulting in the sample with bioactive characteristics similar $(p>0.05)$ to the predicted one. Based on these results, the optimized conditions obtained could be used for the encapsulation of bioactive compounds from beetroot juice with soybean proteins. The resulting encapsulates, with favorable physicochemical characteristics, have a potential to be used in the food industry as food colorants and as components of functional foods.

\section{RESEARCH FUNDING}

This work was supported by the Ministry of Education, Science and Technological Development of Serbia under Grant no. TR31044.

\section{CONFLICT OF INTEREST}

The authors declare no conflict of interest.

\section{REFERENCES}

1. Ahmed, M., Akter, M.S., Lee, J.C., Eun, J.B. (2010). Encapsulation by spray drying of bioactive components, physicochemical and morphological properties from purple sweet potato. $L W T-$ Food Science and Technology, 43, 1307-1312.

2. Ampleatil, N.M., Miraje, S.Y., Patil, P.D., Sahoo, A.K., Mote, G.V. (2015). Natural color extraction from amaranth and beetroot: a review. Indian Journal of Applied Research, 5(5), 19-20.

3. Bazaria, B., Kumar, P. (2018). Optimization of spray drying parameters for beetroot juice powder using response surface methodology (RSM). Journal of the Saudi Society of Agricultural Sciences, 17(4), 408-415.

4. Bhusari, S.N., Muzaffar, K., Kumar, P. (2014). Effect of carrier agents on physical and microstructural properties of spray dried tamarind pulp powder. Powder Technology, 266, 354-364.

5. Brand-Williams, W., Cuvelier, M.E., Berset, C. (1995). Use of free radical method to evaluate antioxidant activity. $L W T-$ Food Science and Technology, 28(1), 25-30.

6. Ceballos, A.M., Giraldo, G.I., Orrego, C.E. (2012). Effect of freezing rate on quality parameters of freeze dried soursop fruit pulp. Journal of Food Engineering, 111(2), 360-365.

7. Chen, C., Chi, Y.J., Xu, W. (2012). Comparisons on the functional properties and antioxidant activity of spray-dried and freezedried egg white protein hydrolysate. Food and Bioprocess Technology, 5(6), 2342-2352.

8. Cheng, D.M., Kuhn, P., Poulev, A., Rojo, L.E., Lila, M.A., Raskin, I. (2012). In vivo and in vitro antidiabetic effects of aqueous cinnamon extract and cinnamon polyphenol-enhanced food matrix. Food Chemistry, 135(4), 2994-3002.

9. Chevallier, A. (1996). The Encyclopedia of Medicinal Plants. A practical reference guide to over 550 key herbs and their medicinal uses, DK Publishing Inc., New York, USA, p. 336.

10. Delgado-Vargas, F., Jimenez, A.R., Paredes-Lopez, O. (2000). Natural pigments: carotenoids, anthocyanins, and betalains characteristics, biosynthesis, processing, and stability. Critical Reviews in Food Science and Nutrition, 40(3), 173-289.

11. de Vos, P., Faas, M.M., Spasojevic, M., Sikkema, J. (2010). Encapsulation for preservation of functionality and targeted delivery of bioactive food components. International Dairy Journal, 20(4), SI, 292-302.

12. do Carmo, E.L., Teodoro, R.A.R., Félix, P.H.C., Fernandes, R.V.B., de Oliveira, É.R., Veiga, T.R.L.A., Borges, S.V., Botrel, D.A. (2018). Stability of spray-dried beetroot extract using oligosaccharides and whey proteins. Food Chemistry, 249, 51-59.

13. Ezhilarasi, P.N., Indrani, D., Jena, B.S., Anandharamakrishnan, C. (2013). Freeze drying technique for microencapsulation of Garcinia fruit extract and its effect on bread quality. Journal of Food Engineering, 117(4), 513-520.

14. Franzen, K.L., Kinsella, J.E. (1976). Functional properties of succinylated and acetylated soy protein. Journal of Agricultural and Food Chemistry, 24(4), 788-795.

15. Gandía-Herrero, F., Cabanes, J., Escribano, J., García-Carmona, F., Jiménez-Atiénzar, M. (2013). Encapsulation of the most potent antioxidant betalains in edible matrixes as powders of different colors. Journal of Agricultural and Food Chemistry, 61 (18), 4294-4302.

16. Georgiev, V.G., Weber, J., Kneschke, E.M., Denev, P.N., Bley, T., Pavlov, A.I. (2010). Antioxidant activity and phenolic content 
of betalain extracts from intact plants and hairy root cultures of the red beetroot Beta vulgaris cv. Detroit dark red. Plant Foods for Human Nutrition, 65(2), 105-111.

17. González-Molina, E., Moreno, D.A., García-Viguera, C. (2008) Genotype and harvest time influence the phytochemical quality of Fino lemon juice (Citrus limon (L.) Burm. F.) for industrial use. Journal of Agricultural and Food Chemistry, 56(5), 1669-1675.

18. Herbach, K.M., Stintzing, F.C., Carle, R. (2006). Betalain stability and degradation - Structural and chromatic aspects. Journal of Food Science, 71 (4), R41-R50.

19. Jafari, S.M., Mahdavi-Khazaei, K., Hemmati-Kakhki, A. (2016). Microencapsulation of saffron petal anthocyanins with cress seed gum compared with Arabic gum through freeze drying. Carbohydrate Polymers, 140, 20-25.

20. Janiszewska, E. (2014). Microencapsulated beetroot juice as a potential source of betalain. Powder Technology, 264, 190-196.

21. Jayasundera, M., Adhikari, B., Aldred, P., Ghandi, A. (2009). Surface modification of spray dried food and emulsion powders with surface-active proteins: A review. Journal of Food Engineering, 93(3), 266-277.

22. Krajka-Kuzniak, V., Szaefer, H., Ignatowicz, E., Adamska, T., Baer-Dubowska, W. (2012). Beetroot juice protects against Nnitrosodiethylamine-induced liver injury in rats. Food and Chemical Toxicology, 50(6), 2027-2033.

23. Kuck, L.S., Noreňa, C.P.Z. (2016). Microencapsulation of grape (Vitis labrusca var. Bordo) skin phenolic extract using gum Arabic, polydextrose, and partially hydrolyzed guar gum as encapsulating agents. Food Chemistry, 194, 569-576.

24. Kujala, T.S., Loponen, J.M., Klika, K.D., Pihlaja, K. (2000). Phenolics and betacyanins in red beetroot (Beta vulgaris) root: distribution and effect of cold storage on the content of total phenolics and three individual compounds. Journal of Agricultural and Food Chemistry, 48(11), 5338-5342.

25. Kujala, T.S., Vienola, M.S., Klika, K.D., Loponen, J.M., Pihlaja, K. (2002). Betalain and phenolic compositions of four beetroot (Beta vulgaris) cultivars. European Food Research and Technology, 214(6), 505-510.

26. López-Varela, S., Gonzalez-Gross, M., Marcos, A. (2002). Functional foods and the immune system: A review. European Journal of Clinical Nutrition, 56(S3), S29-33.

27. Maltais, A., Remondetto, G.E., Subirade, M. (2009). Soy protein cold-set hydrogels as controlled delivery devices for nutraceutical compounds. Food Hydrocolloids, 23(7), 1647-1653.

28. Maltais, A., Remondetto, G.E., Subirade, M. (2010). Tabletted soy protein cold-set hydrogels as carriers of nutraceutical substances. Food Hydrocolloids, 24(5), 518-524.

29. Man, Y.B.C., Irwandi, J., Abdullah, W.J.W. (1999). Effect of different types of maltodextrin and drying methods on physicochemical and sensory properties of encapsulated durian flavour. Journal of the Science of Food and Agriculture, 79(8), 1075-1080.

30. Markham, K.R. (1989). Flavones, Flavonols and their Glycosides. In J.B. Harborne \& P.M. Dey (Eds.), Methods in Plant Biochemistry. Academic Press, London, UK, pp. 197-235.

31. McCord, J.M. (2000). The evolution of free radicals and oxidative stress. American Journal of Medicine, 108(8), 652-659.

32. Medina-Torres, L., García-Cruz, E.E., Calderas, F., Laredo, R.F.G., Sánchez-Olivares, G., Gallegos-Infante, J.A., Rocha-Guzman, N.E., Rodriguez-Ramírez, J. (2013). Microencapsula- tion by spray drying of gallic acid with nopal mucilage (Opuntia ficus indica). LWT - Food Science and Technology, 50(2), 642-650.

33. Nedovic, V., Kalusevic, A., Manojlovic, V., Levic, S., Bugarski, B. (2011). An overview of encapsulation technologies for food applications. Procedia Food Science, 1, 1806-1815.

34. Otálora, M.C., Carriazo, J.G., Iturriaga, L., Nazareno, M.A., Osorio, C. (2015). Microencapsulation of betalains obtained from cactus fruit (Opuntia ficus-indica) by spray drying using cactus cladode mucilage and maltodextrin as encapsulating agents. Food Chemistry, 187, 174-181.

35. Oyaizu, M. (1986). Studies on product of browning reaction from glucose amine. Japanese Journal of Nutrition and Dietetics, 44(6), 307-315.

36. Pitalua, E., Jimenez, M., Vernon-Carter, E.J., Beristain, C.I. (2010). Antioxidative activity of microcapsules with beetroot juice using gum Arabic as wall material. Food and Bioproducts Processing, 88(C2-3), 253-258.

37. Poljsak, B., Šuput, D., Milisav, I. (2013). Achieving the balance between ROS and antioxidants: When to use the synthetic antioxidants. Oxidative Medicine and Cellular Longevity, 2013, art. no. 956792 .

38. Ramírez, M.J., Giraldo, G.I., Orrego, C.E. (2015). Modelling and stability of polyphenol in spray-dried and freeze-dried fruit encapsulates. Powder Technology, 277, 89-96.

39. Ravichandran, K., Saw, N.M.M.T., Mohdaly, A.A.A., Gabr, A.M.M., Kastell, A., Riedel, H., Cai, Z.Z., Knorr, D., Smetanska, I. (2013). Impact of processing of red beet on betalain content and antioxidant activity. Food Research International, 50(2), SI, 670-675.

40. Robert, P., Gorena, T., Romero, N., Sepulveda, E., Chavez, J., Sáenz, C. (2010). Encapsulation of polyphenols and anthocyanins from pomegranate (Punica granatum) by spray drying. International Journal of Food Science and Technology, 45(7), 1386-1394.

41. Rocha-Parra, D.F., Lanari, M.C., Zamora, M.C., Chirife, J. (2016). Influence of storage conditions on phenolic compounds stability, antioxidant capacity and colour of freeze-dried encapsulated red wine. LWT - Food Science and Technology, 70, 162-170.

42. Roopchand, D.E., Krueger, C.G., Moskal, K., Fridlender, B., Lila, M.A., Raskin, I. (2013). Food-compatible method for the efficient extraction and stabilization of cranberry pomace polyphenols. Food Chemistry, 141 (4), 3664-3669.

43. Rouanet, J.M., Decorde, K., Del Rio, D., Auger, C., Borges, G., Cristol, J.-P., Lean, M.E.J., Crozier, A. (2010). Berry juices, teas, antioxidants and the prevention of atherosclerosis in hamsters. Food Chemistry, 118(2), 266-271.

44. Şahin Nadeem, H., Torun, M., Özdemir, F. (2011). Spray drying of the mountain tea (Sideritis stricta) water extract by using different hydrocolloid carriers. LWT - Food Science and Technology, 44(7), 1626-1635.

45. Saikia, S., Mahnot, N.K., Mahanta, C.L. (2015). Optimisation of phenolic extraction from Averrhoa carambola pomace by response surface methodology and its microencapsulation by spray and freeze drying. Food Chemistry, 171, 144-152.

46. Shahidi, F., Han, X.Q. (1993). Encapsulation of food ingredients. Critical Reviews in Food Science and Nutrition, 33(6), 501-547.

47. Sinija, V.R., Mishra, H.N., Bal, S. (2007). Process technology for production of soluble tea powder. Journal of Food Engineering, 82(3), 276-283. 
48. Tonon, R.V., Brabet, C., Hubinger, M.D. (2010). Anthocyanin stability and antioxidant activity of spray-dried açai (Euterpe oleracea Mart.) juice produced with different carrier agents. Food Research International, 43(3), 907-914.

49. Tumbas Šaponjac, V., Ćetković, G., Čanadanović-Brunet, J., Pajin, B., Djilas, S., Petrović, J., Lončarević, I., Stajčić, S., Vulić, J. (2016). Sour cherry pomace extract encapsulated in whey and soy proteins: Incorporation in cookies. Food Chemistry, 207, 27-33.

50. Valko, M., Leibfritz, D., Moncol, J., Cronin, M. T.D., Mazur, M., Telser, J. (2007). Free radicals and antioxidants in normal physiological functions and human disease. International Journal of Biochemistry and Cell Biology, 39(1), 44-84.

51. Vergara, C., Saavedra, J., Sáenz, C., García, P., Robert, P. (2014). Microencapsulation of pulp and ultrafiltered cactus pear (Opuntia ficus-indica) extracts and betanin stability during storage. Food Chemistry, 157, 246-251.

52. Von Elbe, J.H. (2003). Betalains. In R.E. Wrolstad, T.E. Acree, E.A. Decker, M.H. Penner, D.S., Reid, S.J. Schwartz, C.F. Shoemaker, D.M. Smith, P. Sporns (Eds.), Handbook of Food Analyti- cal Chemistry. Pigments, Colorants, Flavors, Texture, and Bioactive Food Components. John Wiley and Sons, Inc., New York, USA, pp. 123-131.

53. Wootton-Beard, P.C., Ryan, L. (2011). A beetroot juice shot is a significant and convenient source of bioaccessible antioxidants. Journal of Functional Foods, 3(4), 329-334.

54. Wruss, J., Waldenberger, G., Huemer, S., Uygun, P., Lanzerstorfer, P., Müller, U., Höglinger, O., Weghuber, J. (2015). Compositional characteristics of commercial beetroot products and beetroot juice prepared from seven beetroot varieties grown in Upper Austria. Journal of Food Composition and Analysis, 42, 46-55.

55. Zielinska-Przyjemska, M., Olejnik, A., Dobrowolska-Zachwieja, A., Grajek, W. (2009). In vitro effects of beetroot juice and chips on oxidative metabolism and apoptosis in neutrophils from obese individuals. Phytotherapy Research, 23(1), 49-55.

Submitted: 27 August 2019. Revised: 15 October, 13 November, 27 November, and 6 December 2019. Accepted 9 December 2019. Published on-line: 30 January 2020. 